OCCASIONAL REVIEW

\title{
Roles of epidermal growth factor receptor activation in epithelial cell repair and mucin production in airway epithelium
}

\author{
P-R Burgel, J A Nadel
}

Thorax 2004;59:992-996. doi: 10.1136/thx.2003.018879

The epithelial cells lining the airways serve protective functions. The "barrier function" of the epithelium protects the individual from damage by inhaled irritants. The epithelium produces mucins which become hydrated and form a viscoelastic gel which spreads over the epithelial surface. In healthy individuals inhaled foreign materials become entrapped in the mucus and are cleared by mucociliary transport and by coughing. In many chronic inflammatory airway diseases, however, excessive mucus is produced and is inadequately cleared, leading to mucous obstruction and infection. At present there is no specific treatment for hypersecretion. However, the discovery that an epidermal growth factor receptor (EGFR) cascade is involved in mucin production by a wide variety of stimuli suggests that blockade may provide specific treatment for hypersecretory diseases. EGFR pathways have also been implicated in the repair of damaged airway epithelium. The roles of EGFR in airway epithelial cell hypersecretion and epithelial damage and repair are reviewed and future potential treatments are suggested.

See end of article for authors' affiliations

Correspondence to: Dr P-R Burgel, Service de Pneumologie, Hôpital Cochin, Université René Descartes, 27 rue du Faubourg St Jacques, 75 679 Paris Cedex 14, France; pierre-regis.burgel@ cch.ap-hop-paris.fr

Received

25 February 2004

Accepted 4 June 2004
$\mathrm{T}$ he epithelial cells lining the airways serve protective functions. The "barrier function" of the epithelium serves to protect the individual from damage by inhaled irritants, including bacteria, viruses, particulates and vapour phase irritants. Normally, mucus secretion plays a protective role. The epithelium produces mucins which are highly glycosylated proteins synthesised by surface epithelial (goblet) cells and by submucosal gland (mucous) cells. When mucins are released from cells (by degranulation) they become hydrated and form a viscoelastic gel which spreads over the epithelial surface. At least 19 mucin genes (MUC) have been cloned. There are two types of respiratory mucins-membrane-associated and gel-forming (secreted). ${ }^{1}$ Three secreted mucins appear to be prominent in inflammatory airway diseases: MUC5AC (in airway epithelial goblet cells), ${ }^{23}$ MUC5B in submucosal glands, ${ }^{4}$ and MUC2 (in goblet cells and glands)..$^{5-7}$ In healthy individuals, inhaled foreign materials become entrapped in the mucus and are cleared by mucociliary transport and by coughing. However, in many chronic inflammatory airway diseases excessive mucus is produced and is inadequately cleared, leading to mucous obstruction and infection. Airway mucus hypersecretion and plugging have been related to death in acute asthma and to proliferation of Pseudomonas aeruginosa in cystic fibrosis. Furthermore, in both asthmatic patients and those with chronic obstructive pulmonary disease (COPD), chronic excessive sputum production is independently associated with an accelerated rate of decline in maximal expiratory flow. ${ }^{8}$

At present there is no specific treatment for hypersecretion. However, the discovery that an epidermal growth factor receptor (EGFR) cascade is involved in mucin production by a wide variety of stimuli suggests that blockade may provide specific treatment for hypersecretory diseases. EGFR pathways have also been implicated in the repair of damaged airway epithelium. This paper reviews the roles of EGFR in airway epithelial cell hypersecretion and epithelial damage and repair and suggests future potential treatments.

EGF was discovered by Cohen and subsequently his group expanded our understanding of EGF and its receptor EGFR. ${ }^{9}$ EGFR is a $170 \mathrm{kDa}$ membrane glycoprotein which is activated by multiple ligands including EGF, transforming growth factor (TGF)- $\alpha$, heparin binding (HB)-EGF, amphiregulin, $\beta$-cellulin and epiregulin, all of which are synthesised as transmembrane precursors (proligands) that are inserted in the cell surface and cleaved by proteases to release the mature soluble growth factor. ${ }^{10}$ The EGFR signalling pathway has been known to be involved in a variety of physiological responses including proliferation, differentiation, motility, and survival. ${ }^{11}{ }^{12}$ Because of the potential importance of the EGFR pathway in airway diseases and potentially in treatment, this paper focuses on mechanisms involved in mucus hypersecretion and in epithelial damage and repair.

\section{ROLE OF EGFR IN MUCIN SYNTHESIS AND GOBLET CELL METAPLASIA}

EGFR activation has been shown to induce epithelial cell proliferation in lung cancer cells under some circumstances such as sparse cultures. Takeyama et $a l^{13}$ reasoned that epithelial cells under other circumstances (such as dense cultures) could stimulate cell differentiation and mucin production. They showed that dense cultures of airway epithelial (NCI-H292) cells

Abbreviations: EGFR, epidermal growth factor receptor; IL, interleukin; TGF, transforming growth factor; TNF, tumour necrosis factor 
resulted in MUC5AC mucin gene expression and protein production. They also showed that addition of EGFR ligands (EGF and TGF- $\alpha$ ) to the densely cultured epithelial cells upregulates MUC5AC gene and protein expression in airway epithelial cells in vitro. Using selective inhibitors of EGFR tyrosine kinase phosphorylation, they reported that EGFR ligand induced mucin MUC5AC synthesis is dependent on EGFR activation. ${ }^{13}$ Perrais et al ${ }^{14}$ confirmed that EGF and TGF- $\alpha$ induce MUC5AC and MUC2 mucin synthesis in airway epithelial cells.

Takeyama et al ${ }^{13}$ extended these findings by studying mechanisms of goblet cell metaplasia in rat trachea in vivo. Tumour necrosis factor- $\alpha$ induces EGFR expression in airway epithelial cells. Subsequent administration of an EGFR ligand (EGF, TGF- $\alpha$ ) caused EGFR activation of a downstream cascade, leading to mucin production (fig 1). From these studies, the authors concluded that activation of airway EGFR causes mucin production. After these original studies, several reports identified EGFR as a key target leading to mucin synthesis and/or goblet cell metaplasia in response to various stimuli (box 1 ).

\section{ROLE OF EGFR IN AIRWAY EPITHELIAL REPAIR}

The role of EGFR activation in mediating epithelial repair has been shown in various cell types in vitro including keratinocytes, $^{26}$ mammary epithelial cells, ${ }^{27}$ and alveolar epithelial cells. ${ }^{28}$ In 1993 Barrow et al ${ }^{29}$ hypothesised that EGFR ligands and other growth factors mediate bronchial epithelial repair. They showed that administration of aerosolised EGF plus PDGF for 2 weeks enhanced repair of sheep tracheal epithelium after cotton smoke injury in vivo. It was suggested that cell proliferation and differentiation were responsible for accelerated epithelial restitution, but the cellular mechanisms were not identified. Kim et $a l^{30}$ hypothesised that EGF accelerates wound closure in airway epithelial

Box 1 Examples of stimuli that induce mucin synthesis in vitro or in vivo by EGFR activation in airways

In vitro experiments

- Bacterial products:

- P aeruginosa supernatant ${ }^{15}$

- Lipopolysaccharide (LPS) ${ }^{15} 16$

- Lipoteichoic acid (LTA) ${ }^{17}$

- Phorbol 12-myristate 13-acetate (PMA) ${ }^{16}$

- Cigarette smoke ${ }^{18}$

- Inflammatory cells:

- Neutrophils ${ }^{19}$

- Eosinophils ${ }^{20}$

- Serine proteases:

- Human neutrophil elastase ${ }^{21}$

- Human airway trypsin-like protease ${ }^{22}$

In vivo experiments

- Th2 cells

- Antigen (ovalbumin) ${ }^{13}$

- IL-1323

- Mechanical damage of epithelium ${ }^{24}$

- Cigarette smoke ${ }^{18}$

- Leukotrienes ${ }^{25}$ cells independently of cell proliferation. Culturing guinea pig airway epithelial cells in vitro, they found that EGF accelerates closure of small wounds in confluent epithelial monolayers over 24 hours and that EGF elicits migration of airway epithelial cells, suggesting that early events in EGF mediated wound closure involve cell migration. Subsequent work in cultured human airway (16HBE 140-) epithelial cells showed that EGF induced epithelial repair occurs within 18 hours and that cell proliferation does not occur at this time, $^{31}$ establishing that EGF promotes airway epithelial repair via cell migration in this model. However, it is likely that cell proliferation is implicated in the repair of larger wounds in the airway epithelium. Puddicombe et al ${ }^{32}$ showed that both EGF and another EGFR ligand, heparin binding EGF (HB-EGF), promote wound closure in airway epithelial cells. Using a selective EGFR tyrosine kinase inhibitor (AG 1478), they implicated EGFR activation in ligand induced wound closure. Because inhibition of EGFR tyrosine kinase phosphorylation also inhibited wound closure under basal conditions (serum free culture medium), the authors suggested that autocrine mechanisms are involved in EGFR mediated repair mechanisms in airway epithelial cells. Figure 2 shows the suggested steps leading to airway epithelial repair after injury.

\section{MECHANISMS OF EGFR EXPRESSION AND ACTIVATION BY DIFFERENT STIMULI}

The expression of EGFR is sparse in the airway epithelium of pathogen free rodents (rats, mice) and in the upper and lower airways of normal humans. ${ }^{33}$ However, EGFR expression in airway epithelium is increased in response to various inflammatory stimuli including TNF- $\alpha,{ }^{13}$ mechanical damage, ${ }^{24}{ }^{32}$ cigarette smoke, ${ }^{18}$ and inhalation of noxious products such as naphthalene ${ }^{34}$ or bleomycin..$^{35}$

EGFR activation may involve two different pathwaysligand dependent and ligand independent EGFR tyrosine phosphorylation. In ligand dependent EGFR tyrosine phosphorylation, EGFR ligands bind to EGF receptors in the extracellular domain and activate them (fig 3, left side) while, in ligand independent EGFR tyrosine phosphorylation, EGFR tyrosine phosphorylation occurs in the absence of exogenous EGFR ligands (fig 3, right side). Ligand independent EGFR phosphorylation is reported in response to oxidative stress $^{36}$ that can be produced by cigarette smoke ${ }^{18}$ and by activated neutrophils. ${ }^{19}$ However, it was later realised that airway epithelial cells, in addition to expressing EGFR, express EGFR proligands on their surface. As will be seen below, some of these stimuli (such as cigarette smoke) can induce shedding of EGFR proligands from the epithelial cell surface, leading to ligand binding to the receptor and ligand dependent EGFR activation. ${ }^{37}$ Neutrophils are present in the airways of patients with hypersecretory diseases such as COPD, acute severe asthma, and cystic fibrosis and could promote ligand independent EGFR activation and mucin synthesis via the release of oxygen free radicals. Other inflammatory cells (such as macrophages and eosinophils) recruited to the airway epithelium in inflammatory respiratory diseases express EGFR ligands, ${ }^{38}{ }^{39}$ raising the possibility that interactions between these cells and epithelial cells could result in ligand dependent activation of EGFR signalling cascades and mucin production. Borchers et a l $^{40}$ showed that exposure of mice to acrolein, a product of cigarette smoke, results in goblet cell metaplasia. They suggested that the effect was due to macrophage elastase. Kim et $a l^{41}$ have recently shown that macrophages induce mucin production in cultured airway epithelial cells. Burgel et $a^{20}$ showed that isolated human eosinophils, when activated, induce mucin synthesis in cultured airway epithelial cells by EGFR activation. Soluble TGF- $\alpha$ was increased in cell culture 


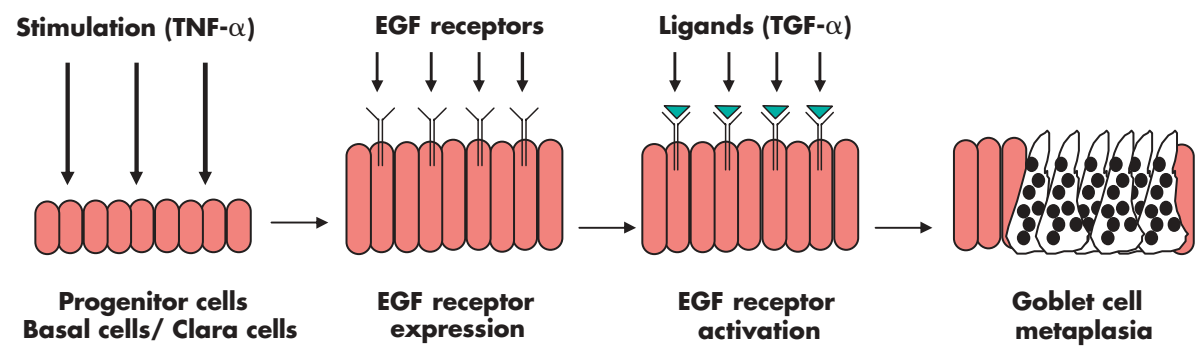

Figure 1 Epidermal growth factor (EGF) receptor expression and activation in goblet cell mucin production. Airway epithelial cells of pathogen free rats and lower airways of healthy humans show sparse expression of EGF receptors. Stimulation by tumour necrosis factor (TNF)- $\alpha$ induces EGFR expression in progenitor cells in airway epithelium but not mucin production. Release of exogenous EGFR ligands (such as transforming growth factor (TGF)- $\alpha$ ) results in ligand binding to EGFR, EGFR activation, and subsequent mucin production in goblet cells (shown by dark granules in light cells).

medium of epithelial cells stimulated with activated eosinophils, and a blocking antibody to TGF- $\alpha$ reduced mucin synthesis. These results implicated an EGFR cascade and suggested that TGF- $\alpha$ is involved in the response.

Airway epithelial cells express several EGFR ligands-for example, EGF, TGF- $\alpha$, HB-EGF, and amphiregulin. ${ }^{42}$ Various stimuli have been reported to increase the expression of selected ligands in experimental models in vitro and in vivo, but mechanisms of inducing this expression are unknown. Among these stimuli are those that induce mucin production-for example, IL-13, ${ }^{43}$ cigarette smoke, ${ }^{44}$ and acrolein ${ }^{1}$ or stimuli used in studies of airway remodelling and repairfor example, vanadium, ${ }^{45}$ bleomycin, ${ }^{35}$ naphthalene, ${ }^{34}$ and compression of bronchial epithelial cells in vitro. ${ }^{46}$

In the epithelium, EGFR proligands are synthesised as membrane anchored molecules that are cleaved by proteases to become activated. ${ }^{10}$ Metalloproteases cleave EGFR proli-

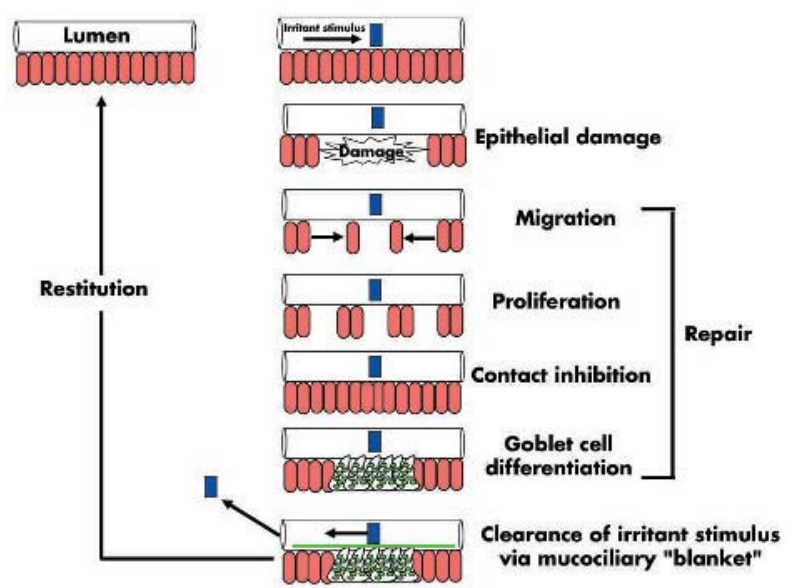

Figure 2 Suggested steps of airway epithelial repair after epithelial damage by irritant stimulus. Normal airway epithelium contains few mucin producing (goblet) cells. Inhalation of foreign particles or noxious agents (dark rectangles) may induce loss of surface airway epithelial cells (epithelial damage) followed by a step by step repair process: (1) migration of epithelial cells from the borders of the wound followed by (2) cell proliferation; (3) when newly formed epithelial cells become confluent they undergo contact inhibition followed by (4) cell differentiation into mucin producing cells. Of course, goblet cell differentiation does not necessarily require prior epithelial damage. Mucus release in the lumen assists in clearance of foreign materials via mucociliary clearance and cough actions on the mucociliary "blanket". The mucus cells then gradually disappear and the epithelial structure returns to normal (epithelial restitution). gands in response to activation by G-protein agonists in mammary epithelial cells. ${ }^{47}$ Lemjabbar et al showed that lipoteichoic acid (LTA), a component of Gram positive bacterial cell walls, induces mucin synthesis by activating EGFR in airway epithelial cells. ${ }^{17}$ Mechanisms of EGFR activation in this model are reported to involve recognition of LTA by platelet activating factor receptor (PAFR), a G-protein coupled receptor that activates a membrane anchored metalloprotease, ADAM 10, resulting in cleavage of proHBEGF, EGFR activation, and mucin synthesis. Shao et al ${ }^{16}$ showed that TNF- $\alpha$ converting enzyme (TACE/ADAM 17), another member of "a disentegrin and metalloprotease" (ADAM) family, is an important regulator of EGFR activation leading to mucin synthesis in airways. Using cultured human airway epithelial cells, these authors showed that phorbol 12myristate 13-acetate (PMA), an activator of TACE, and pathophysiological stimuli (such as lipopolysaccharide (LPS), supernatant of the Gram negative bacteria $P$ aeruginosa, and cigarette smoke) induce mucin synthesis. ${ }^{16}{ }^{37}$ Importantly, knockdown of TACE by specific small interfering RNA prevented EGFR activation and mucin synthesis by these stimuli. Mechanisms involved are cleavage of epithelial membrane anchored proTGF- $\alpha$ by TACE, binding of soluble TGF- $\alpha$ to EGFR, and subsequent phosphorylation of EGFR leading to mucin synthesis. Thus, bacterial products of Gram positive and Gram negative bacteria induce mucin synthesis in airway epithelial cells in vitro by shedding of EGFR proligands leading to autocrine activation of an EGFR cascade. Cleavage of epithelial proligands and autocrine activation of EGFR can also be promoted by neutrophil proteases: Kohri et $a^{l^{21}}$ reported that induction of mucin synthesis by the serine protease human neutrophil elastase (HNE) causes EGFR activation: HNE causes the cleavage of membrane anchored proTGF- $\alpha$ from the epithelial surface resulting in the release of mature TGF- $\alpha$ which binds to EGFR, causing EGFR activation and mucin synthesis. An EGFR blocking antibody inhibited the response to elastase, implicating a ligand dependent process. Voynow et $a l^{48}$ reported that the increase in MUC5AC mRNA following exposure to human neutrophil elastase could be due to increased mRNA stability.

These results implicate EGFR activation by a wide variety of stimuli, and various paracrine interactions among cells and molecules are responsible for the effects on the airway epithelium.

\section{FUTURE CLINICAL STUDIES}

Mucous hypersecretion contributes to morbidity and mortality in various airway inflammatory diseases (such as asthma, COPD, cystic fibrosis, and nasal polyposis), but no treatment to prevent hypersecretion currently exists. Airway mucus 


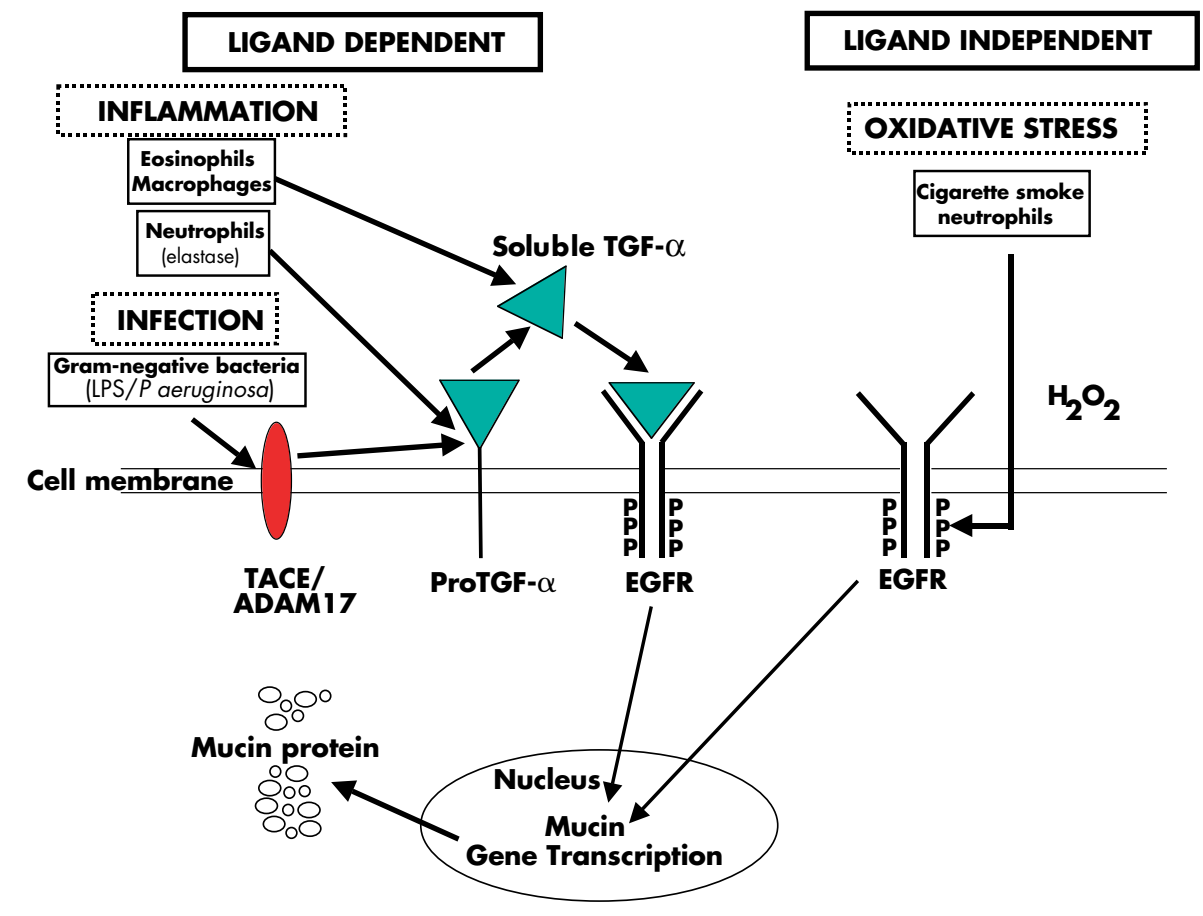

Figure 3 Examples of ligand dependent and ligand independent EGFR activation leading to mucin synthesis. Binding of EGFR ligands (triangles) in the extracellular domain in airway epithelial cells is followed by phosphorylation of tyrosine residues (P) in the intracellular domain (ligand dependent activation). Active (soluble) ligands (exemplified by TGF- $\alpha$ ) may be released by recruited inflammatory cells (such as eosinophils and macrophages) or produced by cleavage of membrane anchored proligand (exemplified by proTGF- $\alpha$ ). The proligand may be cleaved by neutrophil proteases (such as human neutrophil elastase) or by epithelial membrane anchored proteases (such as "a disentegrin and metalloprotease" (ADAM) family exemplified by ADAM 17/TNF- $\alpha$ converting enzyme) in response to stimuli such as $P$ aeruginosa bacteria. Alternatively, activation of EGFR may occur in the absence of ligand binding (ligand independent activation) by phosphorylation of tyrosine residues in the intracellular domain directly (no ligand) in response to stimuli (such as cigarette smoke, activated neutrophils producing oxidative stress). Oxygen free radicals have also been shown to activate shedding of EGFR proligands in epithelial cells resulting in EGFR activation. Regardless of the mechanisms (ligand dependent or ligand independent) of EGFR activation, phosphorylation of tyrosine residues in the intracellular domain triggers a downstream cascade leading to mucin gene and protein synthesis.

hypersecretion can occur with limited clinical symptoms (especially in peripheral airways where cough receptors are absent and where extensive mucous plugging may be undetected by pulmonary function tests), and reproducible biological measurement of mucus production in airway secretions (for example, sputum and bronchoalveolar lavage fluid) in human diseases is difficult. Determining the outcomes in clinical studies of treatments that target mucus hypersecretion in humans is therefore complicated. In a recent study we assessed the effects of an intranasal corticosteroid on mucus production in nasal polyps. ${ }^{49}$ One nasal polyp was removed surgically before treatment and another was removed after 8 weeks of treatment with intranasal fluticasone $(400 \mu \mathrm{g} / \mathrm{day})$ in nine subjects. The polyp tissues were examined morphometrically. Evaluation of alcian blue (AB)/PAS staining for mucus glycoconjugates and staining with a monoclonal antibody to MUC5AC mucin in the epithelium showed that steroids did not affect mucin protein expression. Similarly, MUC5AC mRNA, assessed by in situ hybridisation, was expressed in epithelium before and after treatment, suggesting that intranasal corticosteroids do not reduce mucus production in nasal polyps. We suggest that, because of their location and accessibility, nasal polyps provide a convenient "model" for evaluating various treatments in the suppression of mucin production in the respiratory system.

The finding that various pathophysiological stimuli converge in the EGFR pathway to induce mucin production and goblet cell metaplasia provides new therapeutic opportunities, using treatment targeting mechanisms of EGFR expression or EGFR activation. TNF- $\alpha$ is increased in airways in hypersecretory diseases and may contribute to EGFR expression. ${ }^{13}$ Inhibitors of TNF- $\alpha$ or TNF- $\alpha$ receptors are in clinical use for rheumatoid arthritis and should be evaluated for treating hypersecretion. Small molecules inhibiting EGFR tyrosine kinase phosphorylation or monoclonal antibody to EGFR are undergoing clinical trials in patients with nonsmall cell lung cancer with minimal toxicity. ${ }^{50}$ Clinical studies using molecules targeting EGFR activation in hypersecretory diseases will be of interest. Because various proteases (such as neutrophil elastase and members of the ADAM family of metalloproteases) have been implicated in the cleavage of EGFR proligands and in EGFR activation (see above), it is conceivable that treatments which inhibit these molecules might prevent mucus hypersecretion.

Damage to the airway epithelium has been described in asthma. ${ }^{51}$ EGFR expression is increased in asthmatic epithelium and activation of EGFR contributes to airway epithelial repair. $^{32}$ Because recombinant EGF has been reported to have beneficial effects in ulcerative colitis, ${ }^{52}$ a recent review suggests that the use of recombinant EGF may be beneficial in the treatment of asthma. ${ }^{53}$ In processes where the predominant abnormality is epithelial damage, activation of EGFR may therefore result in improved wound healing. However, in diseases where mucin hypersecretion predominates, inhibition of EGFR phosphorylation could result in reversal of the pathophysiological process.

In conclusion, there is increasing evidence that EGFR is an important player in regulating mucus production in airway epithelium and in the repair of epithelium after injury. Studies performed in recent years have contributed to a better understanding of cellular and molecular mechanisms 
involved in EGFR expression and activation leading to mucin production in response to noxious stimuli. It is suggested that disrupting the EGFR cascade that leads to mucus production is beneficial in airway inflammatory (hypersecretory) diseases. Proof of concept requires clinical trials evaluating new therapeutic opportunities opened by these discoveries.

\section{Authors' affiliations}

P-R Burgel, Service de Pneumologie, Université René Descartes, Hôpital Cochin, Paris, France

J A Nadel, Cardiovascular Research Institute and Departments of Medicine and Physiology, University of California, San Francisco, USA

\section{REFERENCES}

1 Leikauf GD, Borchers MT, Prows DR, et al. Mucin apoprotein expression in COPD. Chest 2002;121(5 Suppl): 166-82S.

2 Ordonez CL, Khashayar R, Wong $\mathrm{HH}$, et al. Mild and moderate asthma is associated with airway goblet cell metaplasia and abnormalities in mucin gene expression. Am J Respir Crit Care Med 2001;163:517-23.

3 Takeyama K, Fahy JV, Nadel JA. Relationship of epidermal growth factor receptors to airway goblet cell production. Am J Respir Crit Care Med $2001 ; 163: 511-6$

4 Sharma P, Dudus L, Nielsen PA, et al. MUC5B and MUC7 are differentially expressed in mucous and serous cells of submucosal glands in human bronchial airways. Am J Respir Cell Mol Biol 1998;19:30-7.

5 Lamblin G, Degroote S, Perini JM, et al. Human airway mucin glycosylation: a combinatory of carbohydrate determinants which vary in cystic fibrosis. Glycoconj J 2001;18:661-84.

6 Li JD, Dohrman AF, Gallup M, et al. Transcriptional activation of mucin by Pseudomonas aeruginosa lipopolysaccharide in the pathogenesis of cystic fibrosis lung disease. Proc Natl Acad Sci USA 1997;94:967-72.

7 Li JD, Feng W, Gallup M, et al. Activation of NF-kappaB via a Src-dependent Ras-MAPK-pp90rsk pathway is required for Pseudomonas aeruginosainduced mucin overproduction in epithelial cells. Proc Natl Acad Sci USA 1998;95:5718-23.

8 Vestbo J. Epidemiological studies in mucus hypersecretion. Novartis Found Symp 2002;248:277-82.

9 Cohen S. Epidermal growth factor. Nobel lecture. Biosci Rep 1986:6:1017-28

10 Dong J, Opresko LK, Dempsey PJ, et al. Metalloprotease-mediated ligand release regulates autocrine signaling through the epidermal growth facto receptor. Proc Natl Acad Sci USA 1999;96:6235-40.

11 O'Hackel P, Zwick E, Prenzel N, et al. Epidermal growth factor receptors: critical mediators of multiple receptor pathways. Curr Opin Cell Biol $1999 ; 11: 184-9$

12 Klapper L, Kirschbaum MH, Sela M, et al. Biochemical and clinical implications of the erbB/HER signaling network of growth factor receptors. Adv Cancer Res 2000;77:25-79.

13 Takeyama K, Dabbagh K, Lee HM, et al. Epidermal growth factor system regulates mucin production in airways. Proc Natl Acad Sci USA 1999;96:3081-6.

14 Perrais M, Pigny P, Copin MC, et al. Induction of MUC2 and MUC5AC mucins by factors of the epidermal growth factor (EGF) family is mediated by EGF receptor/Ras/Raf/extracellular signal-regulated kinase cascade and Sp1. J Biol Chem 2002;277:32258-67.

15 Kohri K, Ueki IF, Shim JJ, et al. Pseudomonas aeruginosa induces MUC5AC production via epidermal growth factor receptor. Eur Respir J 2002;20:1263-70

16 Shao MX, Ueki IF, Nadel JA. Tumor necrosis factor alpha-converting enzyme mediates MUC5AC mucin expression in cultured human airway epithelial cells. Proc Natl Acad Sci USA 2003;100:1 1618-23.

17 Lemjabbar H, Basbaum C. Platelet-activating factor receptor and ADAM10 mediate responses to Staphylococcus aureus in epithelial cells. Nat Med 2002;8:41-6

18 Takeyama K, Jung B, Shim JJ, et al. Activation of epidermal growth factor receptors is responsible for mucin synthesis induced by cigarette smoke. Am J Physiol Lung Cell Mol Physiol 2001;280:L165-72.

19 Takeyama K, Dabbagh K, Shim JJ, et al. Oxidative stress causes mucin synthesis via transactivation of epidermal growth factor receptor: role of neutrophils. J Immunol 2000; 164:1546-52.

20 Burgel PR, Lazarus SC, Tam DC, et al. Human eosinophils induce mucin production in airway epithelial cells via epidermal growth factor receptor activation. J Immunol 2001;167:5948-54.

21 Kohri K, Ueki IF, Nadel JA. Neutrophil elastase induces mucin production by ligand-dependent epidermal growth factor receptor activation. Am J Physiol Lung Cell Mol Physiol 2002;283:L531-40.

22 Chokki M, Yamamura S, Eguchi H, et al. Human airway trypsin-like protease increases mucin gene expression in airway epithelial cells. Am J Respir Cell Mol Biol 2003;30:470-8.

23 Shim JJ, Dabbagh K, Ueki IF, et al. IL-13 induces mucin production by stimulating epidermal growth factor receptors and by activating neutrophils. Am J Physiol Lung Cell Mol Physiol 2001;280:L134-40.

24 Lee HM, Takeyama K, Dabbagh K, et al. Agarose plug instillation causes goblet cell metaplasia by activating EGF receptors in rat airways. Am J Physiol Lung Cell Mol Physiol 2000;278:L185-92.
25 Vargaftig BB, Singer M. Leukotrienes mediate part of Ova-induced lung effects in mice via EGFR. Am J Physiol Lung Cell Mol Physiol 2003;285:L808-18

26 Stoll S, Garner W, Elder J. Heparin-binding ligands mediate autocrine epidermal growth factor activation in skin organ culture. J Clin Invest 1997; 100:1271-81.

27 Matthay MA, Thiery JP, Lafont F, et al. Transient effect of epidermal growth factor on the motility of an immortalized mammary epithelial cell line. J Cell Sci 1993; 106:869-78.

28 Kheradmand F, Folkesson HG, Shum L, et al. Transforming growth factoralpha enhances alveolar epithelial cell repair in a new in vitro model. Am J Physiol 1994;267:L728-38.

29 Barrow RE, Wang CZ, Evans MJ, et al. Growth factors accelerate epithelial repair in sheep trachea. Lung 1993;171:335-44.

$30 \mathrm{Kim}$ JS, McKinnis VS, Nawrocki A, et al. Stimulation of migration and wound repair of guinea-pig airway epithelial cells in response to epidermal growth factor. Am J Respir Cell Mol Biol 1998;18:66-74.

31 White SR, Dorscheid DR, Rabe KF, et al. Role of very late adhesion integrins in mediating repair of human airway epithelial cell monolayers after mechanical injury. Am J Respir Cell Mol Biol 1999;20:787-96.

32 Puddicombe SM, Polosa R, Richter A, et al. Involvement of the epidermal growth factor receptor in epithelial repair in asthma. FASEB $J$ 2000; 14:1362-74

33 Burgel PR, Escudier E, Coste A, et al. Relation of epidermal growth factor receptor expression to goblet cell hyperplasia in nasal polyps.J Allergy Clin Immunol 2000;106:705-12.

34 Van Winkle LS, Isaac JM, Plopper CG. Distribution of epidermal growth factor receptor and ligands during bronchiolar epithelial repair from naphthaleneinduced Clara cell injury in the mouse. Am J Pathol 1997;151:443-59.

35 Madtes DK, Busby HK, Strandjord TP, et al. Expression of transforming growth factor-alpha and epidermal growth factor receptor is increased following bleomycin-induced lung injury in rats. Am J Respir Cell Mol Biol 1994;11:540-51.

36 Goldkorn T, Balaban N, Matsukuma K, et al. EGF-receptor phosphorylation and signaling are targeted by $\mathrm{H}_{2} \mathrm{O}_{2}$ redox stress. Am J Respir Cell Mol Biol 1998; 19:786-98.

37 Shao MX, Nakanaga T, Nadel JA. Cigarette smoke induces MUC5AC mucin overproduction via tumor necrosis factor- $\alpha$ converting enzyme in human airway epithelial (NCl-H292) cells. Am J Physiol Lung Cell Mol Physiol 2004;287:L420-7.

38 Madtes DK, Raines EW, Sakariassen KS, et al. Induction of transforming growth factor-alpha in activated human alveolar macrophages. Cell 1988;53:285-93

39 Wong DTW, Weller PF, Galli SJ, et al. Human eosinophils express transforming growth factor $\alpha$. J Exp Med 1990;172:673-81.

40 Borchers MT, Wesselkamper S, Wert SE, et al. Monocyte inflammation augments acrolein-induced Muc5ac expression in mouse lung. Am J Physiol 1999;277:L489-97.

41 Kim ST, Ueki IF, Shao MX, et al. Macrophages upregulate MUC5AC mucin expression in human airway epithelial cells: roles of TACE and ectodomain shedding of TGF- $\alpha$ in macrophages. Am J Respir Crit Care Med 2004; 169:A536.

42 Polosa R, Prosperini G, Leir SH, et al. Expression of c-erbB receptors and ligands in human bronchial mucosa. Am J Respir Cell Mol Biol 1999;20:914-23.

43 Booth BW, Adler KB, Bonner JC, et al. Interleukin-13 induces proliferation of human airway epithelial cells in vitro via a mechanism mediated by transforming growth factor-alpha. Am J Respir Cell Mol Biol $2001 ; 25: 739-43$.

44 Richter A, O'Donnell RA, Powell RM, et al. Autocrine ligands for the epidermal growth factor receptor mediate interleukin-8 release from bronchial epithelial cells in response to cigarette smoke. Am J Respir Cell Mol Biol 2002;27:85-90.

45 Zhang L, Rice AB, Adler K, et al. Vanadium stimulates human bronchial epithelial cells to produce heparin-binding epidermal growth factor-like growth factor: a mitogen for lung fibroblasts. Am J Respir Cell Mol Biol 2001;24:123-31.

46 Tschumperlin DJ, Shively JD, Swartz MA, et al. Bronchial epithelial compression regulates MAP kinase signaling and HB-EGF-like growth factor expression. Am J Physiol Lung Cell Mol Physiol 2002;282:L904-11.

47 Prenzel N, Zwick E, Daub H, et al. EGF receptor transactivation by G-proteincoupled receptors requires metalloproteinase cleavage of proHB-EGF. Nature 1999:402:884-8

48 Voynow JA, Young LR, Wang Y, et al. Neutrophil elastase increases MUC5AC mRNA and protein expression in respiratory epithelial cells. Am J Physiol Lung Cell Mol Physiol 1999;276:L835-43.

49 Burgel PR, Cardell LO, Ueki IF, et al. Intranasal corticosteroids reduce eosinophils but not mucin expression in nasal polyps. Eur Respir J 2004; $24: 1-7$

50 Herbst RS, Bunn PAJ. Targeting the epidermal growth factor receptor in nonsmall lung cancer. Clin Cancer Res 2003;9:5813-24.

51 Laitinen LA, Heino M, Laitinen A, et al. Damage of the airway epithelium and bronchial reactivity in patients with asthma. Am Rev Respir Dis 1985;131:599-606.

52 Sinha A, Nightingale JMP, West KP, et al. Epidermal growth factor enemas with oral mesalamine for mild-to-moderate left-sided ulcerative colitis or proctitis. N Engl J Med 2003;349:350-7.

53 Holgate ST, Davies DE, Puddicombe SM, et al. Mechanisms of airway epithelial damage: epithelial-mesenchymal interactions in the pathogenesis of asthma. Eur Respir J 2003;22:24-9s. 